\title{
Synthetic Wastewater Treatment using Agro-Based Adsorbents
}

\author{
Saisantosh Vamshi Harsha MADIRAJU, Yung-Tse HUNG* and \\ Howard Hao-Che PAUL
}

Department of Civil and Environmental Engineering, Cleveland State University, Ohio, USA

('Corresponding author's e-mail: yungtsehung@gmail.com)

Received: 23 May 2020, Revised: 26 December 2020, Accepted: 20 January 2021

\begin{abstract}
This study was undertaken to determine the treatment a binary mixture of dye wastewater (containing Naphthol Green B) and the sugar industry wastewater for removal of color. The specific treatment in the current research consists of adsorption using low-cost adsorbents and microfiltration using Whatman-41 microfilters. Considerations of this treatment process are to take the samples using batch adsorption and avoid coagulation with further dilution. Numerous runs are made, with the ideal waste samples prepared in the laboratory. As a $1^{\text {st }}$ step in the study, different dye concentrations are considered using different concentrations of sugar wastewater. Samples are treated with 3 different Agrobased low-cost adsorbents (orange peel, peanut hull, and Powdered Activated Carbon (PAC)). Transmittance values for Naphthol Green B after treatment with orange peel and peanut hull are $83.12 \%$ and $76.98 \%$ respectively. Peanut hull has the highest transmittance of $76.98 \%$ with $<425 \mu \mathrm{m}$ size. Orange peel contributes to the highest transmittance of $83.12 \%$ with a $2 \mathrm{~g}$ dosage. The values of transmittance after treatment with PAC are taken as the datum for the comparison of adsorption performance after treatment using orange peel and peanut hull. Peanut hull has the highest Non-Purgeable Organic Carbon (NPOC) measurement of $37.86 \mathrm{mg} / \mathrm{L}$ when mixed with $600 \mathrm{ppm}$ of sugar wastewater. Similarly, when mixed with $600 \mathrm{ppm}$ of sugar wastewater, orange peel contributes to the NPOC value of $35.06 \mathrm{mg} / \mathrm{L}$. These treated samples using low-cost adsorbents can be considered as pre-treated wastewater that can be sent to municipal wastewater treatment plants.
\end{abstract}

Keywords: Dye wastewater, Sugar wastewater, Adsorption, Absorbance, Transmittance, Microfiltration, Low-cost adsorbents.

\section{Introduction}

Sugar is the most essential substrate in the human diet. In this emerging world, the consumption of sugar is increasing in daily life. More than 115 countries are producing sugar in the world [1]. Since 1789, the United States of America (USA) government has continued to provide support for the domestic sugar industries [2]. Sugar cane and sugar beets are the 2 main sources from which sugar is produced. Sugar is used in candies, soft drinks, cakes, beverages, ice creams, and many other food products. The sugar industry requires massive amounts of water to produce sugar. Many types of pollution loads are released, in the form of solid, liquid, and gaseous states. Chemicals such as $\mathrm{Ca}(\mathrm{OH})_{2}, \mathrm{H}_{3} \mathrm{PO}_{4}, \mathrm{CO}_{2}, \mathrm{SO}_{2}, \mathrm{NaOH}$, $\mathrm{Na}_{2} \mathrm{CO}_{3}$, and $\mathrm{HCL}$ are used in the sugar industry to produce sugar and pre-treatment wastes [3].

The disposal of untreated wastewater from the sugar industry is a major environmental problem. This wastewater contains significant amounts of Total Dissolved Solids (TDS) and Total Suspended Solids (TSS). This water is not useful for irrigation purposes. If disposed on land, the rate of infiltration decreases due to the increase in TDS and TSS. The increase in TSS causes salt deposition, which leads to 
a decrease in soil porosity. Similarly, higher TDS contents are not favorable for crop growth [4]. This shows the typical environmental pollution caused by sugar wastewater.

Dyes are colored aromatic compounds used to impart color on different substrates. They may be organic or inorganic. In the USA, dye additives are used in textiles, food products, cosmetics, drugs, and medical devices [5]. Dyes are classified in several ways based on the source of materials, chromophore, nuclear structure, and industrial classification. Depending on the source of materials, they are classified into natural dyes and synthetic dyes. Depending on chromophore, they are classified into nitro and nitroso dyes, azo dyes, triaryl methane, anthraquinone dyes, and indigo dyes. Depending on the nuclear structure, they are classified into anionic and cationic dyes. According to industrial classification, they are classified into protein textile dyes, cellulose textile dyes, and synthetic textile dyes. Cellulose textile dyes are classified into direct dyes, vat dyes, basic dyes, and fiber reactive dyes. Protein textile dyes are again classified into acid dyes and mordant dyes. Synthetic textile dyes are again classified into disperse dyes and solvent dyes $[5,6]$.

Naphthol Green B comes under industrial dye. The C.I. (Color Index) number is 10020, with the C.I. name of acid green 1. It comes under the class of nitroso with acidic ionization. It is very soluble in aqueous solutions and is green in color. The structure of Naphthol Green B is shown in Figure 1. Its molecular formula is $\left(\mathrm{C}_{10} \mathrm{H}_{5} \mathrm{NO}_{5} \mathrm{SNa}\right)_{3} \mathrm{Fe}$, with a formula weight of $878.79 \mathrm{~g} / \mathrm{mol}$ [7].

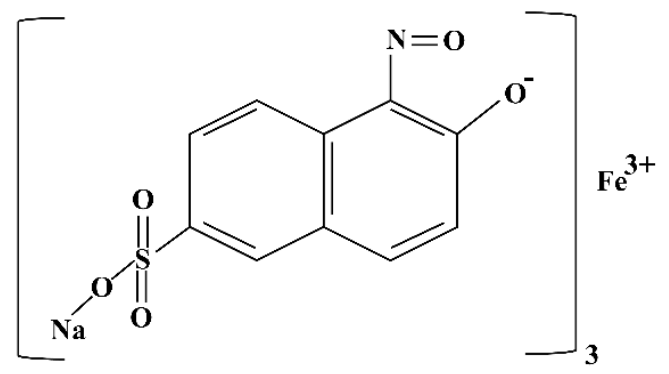

Figure 1 Structure of Naphthol Green B.

\section{Research methodology}

\section{Experimental parameters}

The spectrometer parameters of dye wastewater are transmittance and absorbance. For distilled water, the absorbance and transmittance values are 0 and $100 \%$, respectively. This implies that distilled water has a maximum transmittance capacity of ultraviolet radiation and a minimum absorbance capacity which is nearly zero. Due to this reason, it is considered as the standard measure to calibrate a spectrophotometer.

\section{Transmittance}

Transmittance $(\mathrm{T})$ is a measurement of how much light passes through a substance. The higher the amount of light that passes through, the larger the transmittance. Transmittance is defined as the ratio of the intensity of incident light: the intensity of transmitted light is as given in Eq. (1). At times, this fraction may be represented as a percentage, where it is called the percentage transmittance $(\% \mathrm{~T})$ [8].

$T=\left(\frac{I}{\mathrm{I}}\right)$.

where the intensity of incident light is $I$. and the intensity of transmitted light is I. 


\section{Absorbance}

The expression for Absorbance (A) is given in Eq. (2).

$A=\log _{10}\left(\frac{1}{T}\right)$. in Eq. (3).

Consequently, absorbance can also be given in terms of the percentage transmittance, as represented

$A=2-\log _{10}(\% T)$.

According to Beer-Lambert's law, the absorbance of light, as it passes through a solution, is directly proportional to the path length of light through the material (l) and the concentration (c).

$A=€ \mathrm{lc}$.

where $€$ is a constant called the molar absorptivity. This constant has a specific value for a given substance, provided the temperature of the substance and the wavelength of light passing through it are kept unchanged [8]. This is an extremely useful relationship that allows concentrations of unknown solutions to be found by measuring the absorbance of light through a sample.

\section{Non-Purgeable Organic Carbon (NPOC)}

This comprises all the carbon present after the sample has been acidified and purged with purified air to remove inorganic carbon. Note that volatile organics will be lost during the purging. It is common, but incorrect, for laboratories to measure NPOC, but report it as Total Organic Carbon (TOC). In the Shimadzu TOC-L machine for the addition method, the parameters Purgeable Organic Carbon (POC) and NPOC are measured. The TOC is then calculated. Measurement of the non-purgeable organic compounds is done after POC analysis using catalytic combustion at $680{ }^{\circ} \mathrm{C}$ and subsequent determination of the resulting carbon dioxide using non-dispersive infrared sensor (NDIR) detection [9]. The TOC is calculated via the addition shown in Eq. (5).

$\mathrm{TOC}=\mathrm{POC}+\mathrm{NPOC}$.

For the direct method or NPOC method, it is assumed that the sample does not contain any significant amounts of volatile or purgeable organic compounds. According to this assumption, the TOC is directly determined as NPOC. Acidification of the sample is done using a mineral acid (for instance $\mathrm{HCL}$ ) to a $\mathrm{pH}<2$, whereby carbonates and hydrogen carbonates are completely converted to carbon dioxide. The carbon dioxide is removed from the sample solution via a spare gas. Direct NPOC measurement (like TC measurement) is done via oxidation to $\mathrm{CO}_{2}$. Subsequent NDIR detection is conducted. The TOC corresponds to the NPOC, as is given in Eq. (6) [10].

$\mathrm{TOC}=\mathrm{NPOC}$.

\section{Experimental materials}

The materials used in this research work include: (a) Adsorbents: peanut hull, orange peel; (b) Reference Adsorbent: Powdered Activated Carbon (PAC); (c) Wastewater: dye wastewater containing Naphthol Green B, sugar wastewater.

\section{Adsorbents}

The adsorbents used in this study are peel from oranges and the hull of peanuts: (i) peanut hull: The peanut hull is washed with water thoroughly with tap water. Then, they are oven-dried at $70{ }^{\circ} \mathrm{C}$ for $24 \mathrm{~h}$. Then, the dried peanut hull is ground with a Preethi blender and sieved into 4 assorted sizes. The retained matter on 4 sizes sieves is used in this research to treat the combined wastewater of Naphthol Green B and sugar wastewater. This helps us to determine the variation in adsorption capacity due to the change in 
http://wjst.wu.ac.th

the surface area. (ii) orange peel: Ripened oranges are collected, and the peel is taken out separately. The peel is then oven-dried at $70{ }^{\circ} \mathrm{C}$ for $24 \mathrm{~h}$. The dried orange peels are ground with a Preethi blender and sieved. The matter is passed through $425 \mu \mathrm{m}$. Single size is maintained, and the dosage is varied in the case of orange peel.

\section{Reference adsorbent}

The reference adsorbent used in this study is PAC. Its manufacturer is Darco, with its grade HDC. First, the experiment is conducted with PAC, and the results are tabulated. PAC values are used as reference values to compare the treatment capacity of the low-cost adsorbents (peanut hull and orange peel).

\section{Wastewater}

wastewater is prepared in the laboratory with Naphthol Green B and Sugar Powder. Mother samples are prepared with 1,000 ppm with both dye and sugar separately. Then, specific concentrations are fixed based on the trial test performed, resulting in noticeable variance in transmittance. Then, combined wastewater is prepared, with respective concentrations and in different combinations. One hundred $\mathrm{mL}$ is the fixed quantity of combined wastewater, with equal halves of dye and sugar wastewater. The molecular structure of Naphthol Green B is shown in Figure 1.

\section{Experimental Methods}

There are many methods to treat dye wastewater. There are many physio-chemical treatment methods, such as adsorption, coagulation, flocculation, biological treatment, electrochemical oxidation, etc. In this research, the authors mainly concentrate on the combined method of adsorption and microfiltration.

\section{Adsorption}

Adsorption is a surface phenomenon with a common mechanism for organic and inorganic pollutant removal. When a solution containing absorbable solute encounters a solid with a highly porous surface structure, liquid-solid intermolecular forces of attraction cause some of the solute molecules from the solution to be concentrated or deposited on the solid surface. The solute retained (on the solid surface) in adsorption processes is called an adsorbate, whereas the solid on which it is retained is called an adsorbent. This surface accumulation of adsorbate on adsorbent is called adsorption. This creation of an adsorbed phase having a composition different from that of the bulk fluid phase forms the basis of separation by adsorption technology [11].

\section{Micro-filtration}

Micro-filtration (or MF for short) is one of the pressure-driven membrane processes in the series micro-filtration, ultra-filtration (UF), nano-filtration (NF), and reverse osmosis (RO). The micro-filtration process uses a membrane- a simple permeable material- which, in the case of micro-filtration, only allows particles smaller than 0.1 microns to pass through it. The microfiltration membrane can consist of various materials like, for example, polysulfide, poly-vinyl-di-fluoride (PVDF), poly-ether-sulfone (PES), $\mathrm{ZrO}_{2}$, and carbon. The pore size varies between 0.1 and 5 microns. Because the pores are large compared to other mentioned filtration techniques, the pressure needed to send the liquid through a micro-filter membrane is limited to 0.1 to 3 bar [12].

\section{Approach}

The experiments are performed by adding adsorbent to $100 \mathrm{~mL}$ of combined wastewater. The orange peel powder is added in 4 different weights of $0.5,1,1.5$, and $2 \mathrm{~g}$ of powder passed through a 425 $\mu \mathrm{m}$ sieve. The 5 assorted sizes (powder retained on 3327 - 2380, 2380 - 2362, 2362 - 600, and 600 - 425 $\mu \mathrm{m},<425 \mu \mathrm{m}$ ) of peanut hull are added at a constant dosage of $2 \mathrm{~g}$ per $100 \mathrm{~mL}$. A mechanical shaker is used to mix the adsorbents thoroughly at $100 \mathrm{rpm}$ for $1 \mathrm{~min}$ and $30 \mathrm{rpm}$ for $45 \mathrm{~min}$. We allow them to 
undergo an adsorption process for $24 \mathrm{~h}$ and filter them with micro-filters (Whatman-41). The absorbance and transmittance values are tabulated before and after the treatment of combined wastewater using a spectrophotometer. The preparation of mother samples, wastewater samples, and treatment is conducted at room temperature $\left(25 \pm 2{ }^{\circ} \mathrm{C}\right)$ unless otherwise stated. The adsorption capacity at equilibrium is calculated using the following Eq. (7):

$q_{e}=\frac{(\mathrm{Co}-\mathrm{Ce}) x \mathrm{~V}}{W}$

where,

Co is the initial concentration (ppm)

$\mathrm{Ce}$ is the equilibrium after treatment (ppm)

$\mathrm{V}$ is the volume of each sample considered $(\mathrm{mL})$

$\mathrm{W}$ is the weight of adsorbent added $(\mathrm{g} / \mathrm{L})$

The details of the types of equipment used to perform the experiments are mentioned in Table $\mathbf{1}$.

Table 1 Details of the instruments used for the current study.

\begin{tabular}{lll}
\hline \multicolumn{1}{c}{ Name } & \multicolumn{1}{c}{ Model } & \multicolumn{1}{c}{ Application } \\
\hline Weighing Balance & OHAUS PA1502 & An instrument used to measure sensitive weights. \\
Spectrophotometer & $\begin{array}{l}\text { Carolina } \\
\# 65-3303\end{array}$ & $\begin{array}{l}\text { An instrument used to measure transmittance and absorbance at } \\
\text { an adjustable wavelength with spectral bandpass. }\end{array}$ \\
Platform Shaker & $\begin{array}{l}\text { Innova 2300- } \\
(115 \mathrm{~V} 60 \mathrm{CV} \text { AC) })\end{array}$ & $\begin{array}{l}\text { An instrument that provides vibration to ensure proper mixing of } \\
\text { samples. }\end{array}$ \\
TOC Analyzer & Shimadzu TOC-L & $\begin{array}{l}\text { An instrument that adopts combustion catalytic oxidation } \\
\text { method and measures TC, TOC, NPOC, etc., }\end{array}$ \\
Fisher Oven & $\begin{array}{l}\text { 200 SERIES } \\
\text { (Model 230F) }\end{array}$ & $\begin{array}{l}\text { A conventional benchtop laboratory oven with accurate control } \\
\text { of the temperature. }\end{array}$ \\
\hline
\end{tabular}

\section{Run protocols}

Tables 2 and 3 are the run protocols for this research study. Table 2 represents the run protocols for high concentration dye treated with PAC and orange peel. Table 3 represents the run protocols for high concentration dye treated with peanut hull. The parameters which are varied in this research consist of the concentration of dye wastewater and the concentration of sugar wastewater, type of adsorbent, and weight (dosage) of adsorbent.

Table 2 Run protocols for high concentration dye treated with PAC and orange peel.

\begin{tabular}{cccc}
\hline Run order & Dye concentration (ppm) & Adsorbent weight (g) & Sugar wastewater concentration (ppm) \\
\hline 1 & 200 & 0.5 & 100 \\
2 & 200 & 1 & 100 \\
3 & 200 & 1.5 & 100 \\
4 & 200 & 2 & 100 \\
5 & 200 & 0.5 & 200 \\
6 & 200 & 1 & 200
\end{tabular}




\begin{tabular}{cccc}
\hline Run order & Dye concentration (ppm) & Adsorbent weight (g) & Sugar wastewater concentration (ppm) \\
\hline 7 & 200 & 1.5 & 200 \\
8 & 200 & 2 & 200 \\
9 & 200 & 0.5 & 300 \\
10 & 200 & 1 & 300 \\
11 & 200 & 1.5 & 300 \\
12 & 200 & 2 & 300 \\
13 & 200 & 0.5 & 400 \\
14 & 200 & 1 & 400 \\
15 & 200 & 1.5 & 400 \\
16 & 200 & 2 & 400 \\
17 & 200 & 0.5 & 500 \\
18 & 200 & 1 & 500 \\
19 & 200 & 1.5 & 500 \\
20 & 200 & 2 & 500 \\
21 & 200 & 0.5 & 600 \\
22 & 200 & 1 & 600 \\
23 & 200 & 1.5 & 600 \\
24 & 200 & 2 & 600 \\
\hline
\end{tabular}

Table 3 Run protocols for high concentration dye treated with peanut hull.

\begin{tabular}{|c|c|c|c|}
\hline $\begin{array}{c}\text { Run } \\
\text { order }\end{array}$ & $\begin{array}{c}\text { Dye concentration } \\
(\mathbf{p p m})\end{array}$ & $\begin{array}{c}\text { Size of the adsorbent } \\
(\mu \mathrm{m})\end{array}$ & Sugar wastewater concentration (ppm) \\
\hline 1 & 200 & $3327-2380$ & 100 \\
\hline 2 & 200 & $2380-2362$ & 100 \\
\hline 3 & 200 & $2362-600$ & 100 \\
\hline 4 & 200 & $600-425$ & 100 \\
\hline 5 & 200 & $<425$ & 100 \\
\hline 6 & 200 & $3327-2380$ & 200 \\
\hline 7 & 200 & $2380-2362$ & 200 \\
\hline 8 & 200 & $2362-600$ & 200 \\
\hline 9 & 200 & $600-425$ & 200 \\
\hline 10 & 200 & $<425$ & 200 \\
\hline 11 & 200 & $3327-2380$ & 300 \\
\hline 12 & 200 & $2380-2362$ & 300 \\
\hline 13 & 200 & $2362-600$ & 300 \\
\hline 14 & 200 & $600-425$ & 300 \\
\hline 15 & 200 & $<425$ & 300 \\
\hline 16 & 200 & $3327-2380$ & 400 \\
\hline 17 & 200 & $2380-2362$ & 400 \\
\hline 18 & 200 & $2362-600$ & 400 \\
\hline 19 & 200 & $600-425$ & 400 \\
\hline 20 & 200 & $<425$ & 400 \\
\hline 21 & 200 & $3327-2380$ & 500 \\
\hline 22 & 200 & $2380-2362$ & 500 \\
\hline 23 & 200 & $2362-600$ & 500 \\
\hline 24 & 200 & $600-425$ & 500 \\
\hline
\end{tabular}




\begin{tabular}{cccc}
\hline $\begin{array}{c}\text { Run } \\
\text { order }\end{array}$ & $\begin{array}{c}\text { Dye concentration } \\
(\mathbf{p p m})\end{array}$ & $\begin{array}{c}\text { Size of the adsorbent } \\
(\boldsymbol{\mu} \mathbf{m})\end{array}$ & Sugar wastewater concentration (ppm) \\
\hline 25 & 200 & $<425$ & 500 \\
26 & 200 & $3327-2380$ & 600 \\
27 & 200 & $2380-2362$ & 600 \\
28 & 200 & $2362-600$ & 600 \\
29 & 200 & $600-425$ & 600 \\
30 & 200 & $<425$ & 600 \\
\hline
\end{tabular}

\section{Results and discussion}

The observations are compared, and the results are tabulated to interpret the performance and behavior of the low-cost adsorbents with 4 different dosages for PAC and orange peel powder $(0.5,1,1.5$, and $2 \mathrm{~g}$ ) and peanut hull retained on 5 different sieve sizes of 3327 - 2380, 2380 - 2362, 2362 - 600, and $600-425 \mu \mathrm{m},<425 \mu \mathrm{m}$ with 4 different dosages of dyes of low, lower medium, upper-medium, and high, and 6 concentrations of sugar wastewater of 100, 200, 300, 400, 500, and $600 \mathrm{ppm}$. The effect of $\mathrm{pH}$, dye concentration, contact time, and surface area are considered while conducting the experiments.

\section{Effect of pH}

$\mathrm{pH}$ is very important in the adsorption process, especially in dye adsorption. The rate of adsorption and the magnitude of electrostatic charges due to ionized dye molecules is controlled by the level of $\mathrm{pH}$, preferably medium. $\mathrm{pH}$ is inversely proportional to anionic dye adsorption and directly proportional to cationic dye adsorption. The initial $\mathrm{pH}$ of the combined wastewater samples is in the range of $6-9$.

\section{Effect of dye concentration}

The initial concentrations of dye taken in this research are considered based on trial and error methods. Trial samples are taken and tested with different concentrations. Suitable concentrations are selected to distinguish the change in transmittance (\%). As the concentration increases, the transmittance value decreases.

\section{Effect of contact time}

During the experiments, the contact time of the combined wastewater samples with the adsorbent is $24 \pm 1 \mathrm{~h}$. The whole experiment for a set of samples is completed in not more than $48 \mathrm{~h}$. The effect of oxidation of dye increases as the duration of the experiment increases.

\section{Effect of surface area}

Orange peel is considered in 4 dosages with the same sieve size (powder passed through $425 \mu \mathrm{m}$ sieve). Peanut hull is added to the same dosage with 5 sieve sizes. The phenomenon observed after treatment is an increase in the rate of adsorption due to an increase in surface area, which has an impact on treatment capacity.

\section{Transmittance (\%)}

The amount of light that can pass through a substance is called transmittance. Distilled water is considered a datum due to its $100 \%$ (maximum) transmissivity. It can also be defined as the ratio of the intensity of incident light to transmitted light. It is measured in \%. The transmittance, when treated with low-cost adsorbents and compared with PAC at optimum dosage and size, is plotted in Figure 2. 
Naphthol Green B, Transmittance at Optimum Dosage and Size

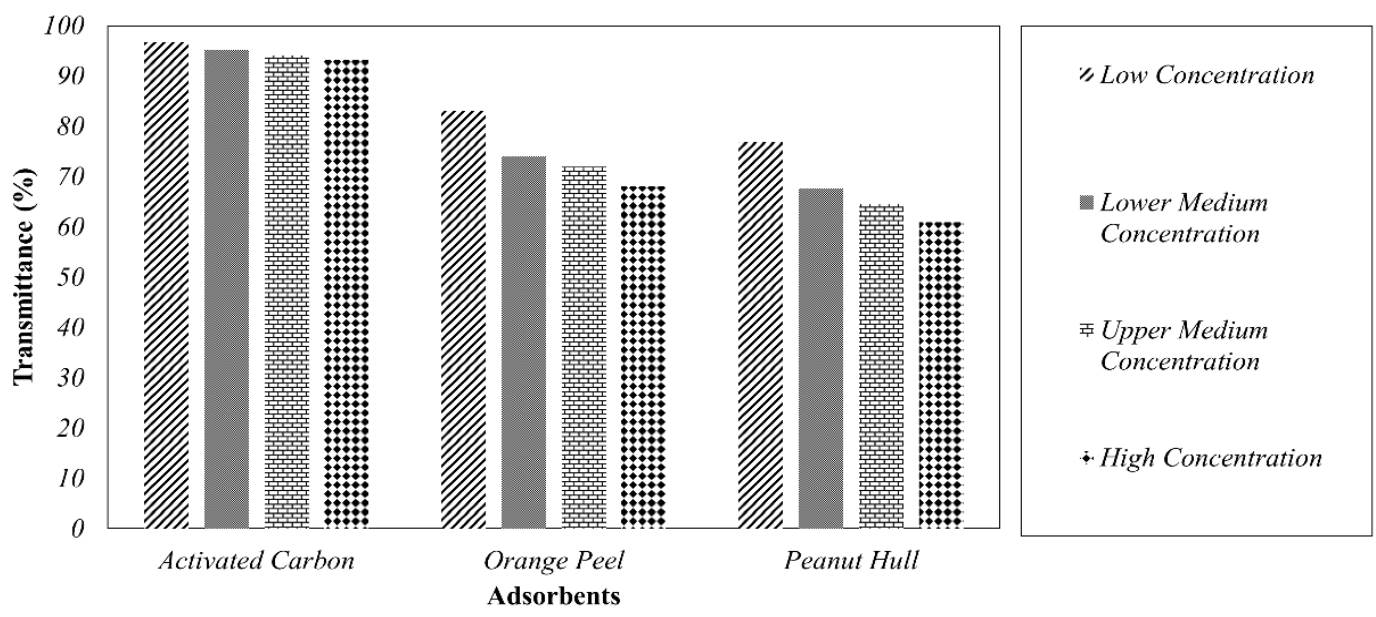

Figure 2 Transmittance of Naphthol Green B at optimum adsorbent size and dosage.

\section{Non-Purgeable Organic Carbon (NPOC)}

non-purgeable organic carbon is the organic carbon that remains after purging the acidified sample with gas. The NPOC for high concentration Naphthol Green B (200 ppm) with increasing sugar wastewater concentration $(\mathrm{mg} / \mathrm{L})$ is shown in Table $\mathbf{4}$ as follows:

Table 4 Comparison of NPOC at high concentration Naphthol Green B.

\begin{tabular}{ccccc}
\hline \multirow{2}{*}{$\begin{array}{c}\text { Sugar Wastewater } \\
\text { Concentration }\end{array}$ (ppm) } & Dye & \multicolumn{2}{c}{ NPOC $(\mathbf{m g} / \mathbf{L})$ for Naphthol Green B (200 ppm) using } \\
\cline { 3 - 5 } Concentration & Activated Carbon & Orange Peel & Peanut Hull \\
\hline 100 & Low & 9.76 & 10.62 & 12.47 \\
100 & Lower medium & 8.62 & 10.91 & 12.83 \\
100 & Upper medium & 8.37 & 11.28 & 13.42 \\
100 & High & 8.57 & 11.74 & 13.91 \\
200 & Low & 15.36 & 16.51 & 18.24 \\
200 & Lower medium & 15.74 & 16.96 & 18.79 \\
200 & Upper medium & 15.43 & 16.26 & 19.18 \\
200 & High & 16.11 & 17.73 & 19.92 \\
300 & Low & 18.29 & 19.13 & 23.47 \\
300 & Lower medium & 17.98 & 19.43 & 23.69 \\
300 & Upper medium & 17.66 & 20.27 & 24.84 \\
300 & High & 16.42 & 20.76 & 26.91 \\
400 & Low & 22.14 & 24.36 & 27.88 \\
400 & Lower medium & 21.63 & 24.83 & 28.43 \\
400 & Upper medium & 20.87 & 25.12 & 28.76 \\
400 & High & 23.47 & 25.63 & 29.38 \\
500 & Low & 27.63 & 29.26 & 32.01 \\
500 & Lower medium & 26.42 & 29.17 & 32.78 \\
500 & Upper medium & 23.21 & 30.24 & 33.11 \\
500 & High & 26.87 & 30.75 & 33.54 \\
600 & Low & 32.17 & 33.43 & 36.41 \\
600 & Lower medium & 31.63 & 33.78 & 36.95 \\
600 & Upper medium & 30.74 & 34.12 & 37.08 \\
600 & High & 29.87 & 35.06 & 37.86 \\
\hline
\end{tabular}


The above table represents the NPOC after treatment with 3 different adsorbents, which is used to describe the relationship between the NPOC and varying sugar wastewater concentrations with 3 different low-cost adsorbents (activated carbon, orange peel, and peanut hull) for a high Naphthol Green B concentration. We can observe that wastewater treated with peanut hull has the high NPOC value of $37.86 \mathrm{mg} / \mathrm{L}$, with orange peel and activated carbon having NPOC values of 35.06 and $32.17 \mathrm{mg} / \mathrm{L}$, respectively. We can also observe that the NPOC values increase with the increase in sugar wastewater concentration from 100 to $600 \mathrm{ppm}$.

\section{Adsorption isotherms}

The equilibrium studies are performed by adding $0.5,1,1.5$, and $2 \mathrm{~g}$ of orange peel powder and $2 \mathrm{~g}$ of 5 assorted sizes of peanut hull to $100 \mathrm{~mL}$ of combined wastewater with 5 different concentrations of Naphthol Green B and 6 different concentrations of sugar wastewater.

The linearized Langmuir Isotherm model is written as Eq. (8):

$$
\frac{1}{q e}=\frac{1}{q m k a} * \frac{1}{C e}+\frac{1}{q m}
$$

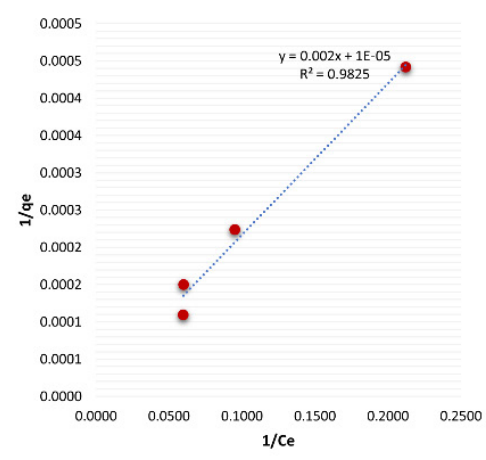

(a)

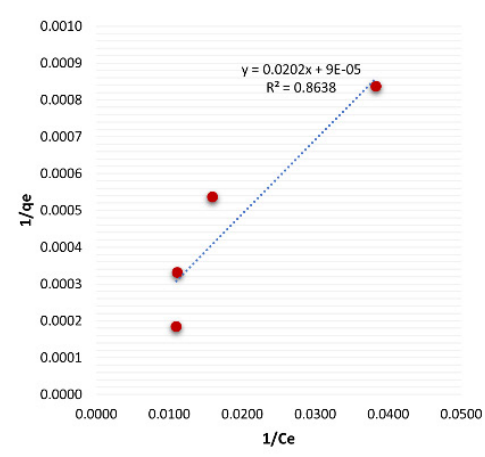

(b)

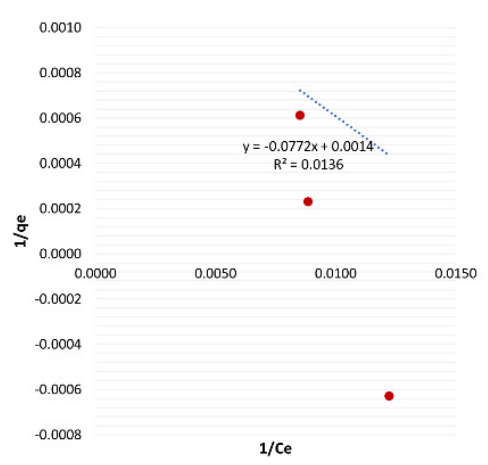

(c)

Figure 3 Langmuir isotherm model of Naphthol Green B adsorption on PAC - (a), on Orange peel - (b), on peanut hull - (c).

The linearized Freundlich Isotherm model is written as Eq. (9):

$q=k * C^{1 / n}$.

The results of linearized Langmuir Isotherms and linearized Freundlich Isotherms of Naphthol Green B when treated with low-cost adsorbents are presented in Figure 4. 


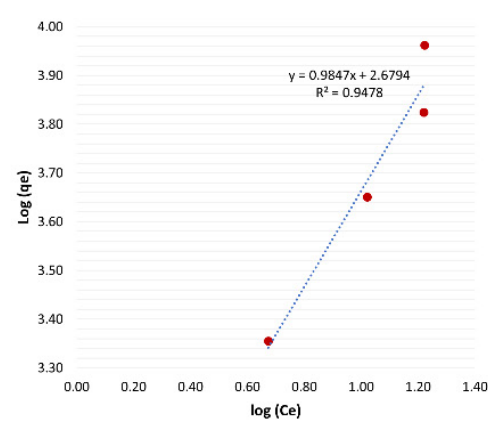

(a)

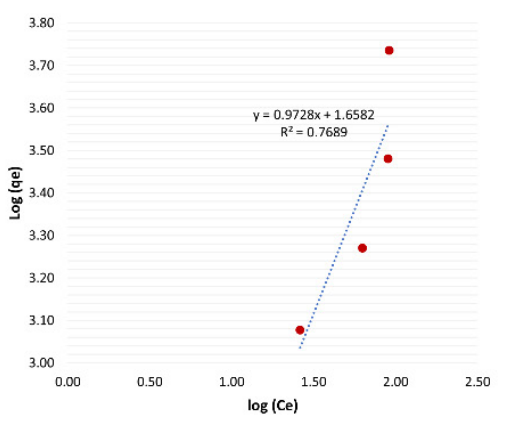

(b)

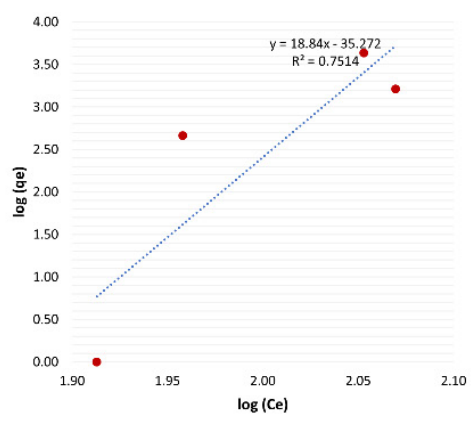

(c)

Figure 4 Freundlich isotherm model of Naphthol Green B adsorption on PAC - (a), on orange peel - (b), on peanut hull - (c).

The Langmuir isotherm model has the best fit for Naphthol Green B at the optimum dosage of lowcost adsorbents with the linear equation: $\mathrm{y}=0.002 \mathrm{x}+0.00001$ and coefficient of determination $\mathrm{R}^{2}=$ 0.9825 .

The study shows the transmittance after treatment with 3 different adsorbents, which is used to describe the relationship between the transmittance and varying dye (Naphthol Green B) concentration with 3 different low-cost adsorbents (activated carbon, orange peel, peanut hull) for the various wastewater samples. The results indicate that the transmittance decreases from 96.72 to $93.17 \%$ with the increase in dye concentration from low to high when treated with activated carbon. Similarly, it is observed that the transmittance decreases from 83.12 to 67.98 and 76.98 to $60.94 \%$ with the increase in dye concentration from low to high when treated with orange peel and peanut hull, respectively. From the change in concentration of sugar wastewater, there is a significant change is observed in the NPOC values. This shows that the pollutants from sugar wastewater are directly proportional to the NPOC values. The conclusions drawn from the study are discussed in the next section.

\section{Conclusions}

Based on the experimental results, it is concluded that orange peel can treat Naphthol Green B, a basic dye in a sugar solution to achieve maximum transmittance (\%) up to $83 \%$ and, similarly, peanut hull up to $76 \%$. Peanut hull has the highest transmittance of $76.98 \%$ with $<425 \mu \mathrm{m}$ size. Orange peel has the highest transmittance of $83.12 \%$ with a $2 \mathrm{~g}$ dosage. The values of transmittance after treatment with PAC are taken as the datum for the comparison of values after the treatment with orange peel and peanut hull. Peanut hull has the highest NPOC value of $37.86 \mathrm{mg} / \mathrm{L}$ when mixed with $600 \mathrm{ppm}$ of sugar wastewater. Orange peel has an NPOC value of $35.06 \mathrm{mg} / \mathrm{L}$ when mixed with $600 \mathrm{ppm}$ of sugar wastewater. These 2 are suggestable low-cost adsorbents to use with Naphthol Green B for color removal. However, the adjustment of $\mathrm{pH}$ is neglected since the considered samples are already in a medium-range $(6-9) \mathrm{pH}$. The NPOC values are high due to the impact of sugar solution. The Langmuir and Freundlich isotherm models represent the equilibrium adsorption of Naphthol Green B on orange peel and peanut hull. The Langmuir isotherm model has the best fit for Naphthol Green B at the optimum dosage of lowcost adsorbents. These treated samples use low-cost adsorbents and can be discharged into surface water through municipal sewage. This research provides insight into dealing with complex wastes. The recommendations for future research include: (i) Adsorption must be studied with different adsorbents and more binary combinations of wastewater effluents from point and non-point sources. (ii) Conducting experiments with different dyes will help to identify the range of treatment capacity of low-cost 
adsorbents. (iii) Recommended research on micro-filters with various pore sizes can give the optimum filtration capacity for different dyes.

\section{References}

[1] International Sugar Organization, Available at: https://www.isosugar.org/sugarsector/sugar, accessed November 2020.

[2] TJ Wiltgen. 2007, An economic history of the United States sugar program. Ph.D. Dissertation. Montana State University, Bozeman, Montana, USA.

[3] M Singh, L Liang, A Basu, MA Belsan, GA Hallsby and T Morris. 3D TRASAR ${ }^{T M}$ technologies for reliable wastewater recycling and reuse. In: VV Ranade and VM Bhandari (Eds.). Industrial wastewater treatment, recycling, and reuse. Butterworth-Heinemann, 2014, p. 435-62.

[4] PK Poddar and O Sahu. Quality and management of wastewater in sugar industry. Appl. Water Sci. 2017; 7, 461-8.

[5] International Agency for Research on Cancer. Some aromatic amines, organic dyes, and related exposures. WHO Press, Lyon, 2010, p. 55-67.

[6] EN Abrahart. Dyes and their intermediates. Chemical, New York, 1977.

[7] JA Kiernan. Classification and naming of dyes, stains and fluorochromes. Biotech. Histochem. 2001; 76, 261-78.

[8] SVH Madiraju. 2018, Color removal and treatment of dye and sugar waste water using low cost adsorbents. Ph.D. Dissertation. Cleveland State University, Ohio, USA.

[9] ASP Pamula, YT Hung and HH Paul. Treatment of combined acid black 48 and coffee wastewater by low-cost adsorbents. J. Environ. Res. Eng. Manag. 2020; 76, 47-61.

[10] ASP Pamula, YT Hung and HH Paul. Treatment of combined disperse yellow 3 and coffee wastewater by low-cost Agro-based adsorbents. Int. J. Mod. Trends Sci. Technol. 2020; 6, 247-53.

[11] ASP Pamula. 2018, Adsorption and microfiltration processes to treat dye and coffee wastewater. Ph.D. Dissertation. Cleveland State University, Ohio, USA.

[12] SVH Madiraju, YT Hung and HH Paul. Treatment of disperse blue 14 wastewater and sugar wastewater by low cost adsorbents. Res. J. Chem. Environ. Sci. 2018; 6, 16-22. 